\title{
Utilization of rye as energy source affects bacterial translocation, intestinal viscosity, microbiota composition, and bone mineralization in broiler chickens
}

\author{
Guillermo Tellez ${ }^{1}$, Juan D. Latorre ${ }^{1}$, Vivek A. Kuttappan ${ }^{1}$, Michael H. Kogut $^{2}$, Amanda Wolfenden ${ }^{1}$, \\ Xochitl Hernandez-Velasco ${ }^{3}$, Billy M. Hargis' ${ }^{1}$, Walter G. Bottje ${ }^{1}$, Lisa R. Bielke ${ }^{1}$ and Olivia B. Faulkner ${ }^{1}$ \\ 'The John Kirkpatrick Skeeles Poultry Health Laboratory, Department of Poultry Science and The Center of Excellence for Poultry Science, University of \\ Arkansas, Fayetteville, AR, USA \\ 2 Southern Plains Area Home, United States Department of Agriculture - Agricultural Research Service, College Station, TX, USA \\ ${ }^{3}$ Facultad de Medicina Veterinaria y Zootecnia, Universidad Nacional Autónoma de México, Mexico City, México
}

\section{Edited by:}

Dimiter Dimitrov, Diavita Ltd., Bulgaria

Reviewed by:

Matthew Philip Greig Barnett, AgResearch Limited, New Zealand Zhe Wang, Weill Medical College of Cornell University, China

\section{${ }^{*}$ Correspondence:}

Guillermo Tellez, The John Kirkpatrick Skeeles Poultry Health Laboratory, Department of Poultry Science and The Center of Excellence for Poultry Science, University of Arkansas, 1260 West Maple, POSC 0-114, Fayetteville, AR 72701, USA e-mail: gtellez@uark.edu
Two independent trials were conducted to evaluate the utilization of rye as energy source on bacterial translocation (BT), intestinal viscosity, gut integrity, gut microbiota composition, and bone mineralization, when compared with a traditional cereal (corn) in broiler chickens. In each experiment, day-of-hatch, broiler chickens were randomly assigned to either a corn or a rye diet ( $n=20$ chickens/group). At $10 \mathrm{~d}$ of age, in both experiments, 12 chickens/group were randomly selected, and given an oral gavage dose of fluorescein isothiocyanate dextran (FITC-d). After $2.5 \mathrm{~h}$ of oral gavage, blood samples were collected to determine the passage of FITC-d. The liver was collected from each bird to evaluate BT. Duodenum, ileum, and cecum gut sections were collected to evaluate intestinal viscosity and to enumerate gut microbiota. Tibias were collected for observation of bone parameters. Broilers fed with rye showed increased $(p<0.05)$ intestinal viscosity, BT, and serum FITC-d. Bacterial enumeration revealed that chickens fed with rye had increased the number of total lactic acid bacteria in all three sections of the gastrointestinal tract evaluated when compared to chickens fed with corn. Chickens fed with rye also had significantly higher coliforms in duodenum and ileum, whereas the total number of anaerobes increased only in duodenum. A significant reduction in bone strength and bone mineralization was observed in chickens fed with rye when compared with corn fed chickens. In conclusion, rye evoked mucosal damage in chickens that alter the intestinal viscosity, increased leakage through the intestinal tract, and altered the microbiota composition as well as bone mineralization. Studies to evaluate dietary inclusion of selected DFM candidates that produce exogenous enzymes in rye fed chickens are currently being evaluated.

Keywords: bacterial translocation, intestinal viscosity, rye, bone mineralization, chickens

\section{INTRODUCTION}

The intestinal epithelium constitutes the largest and most important barrier against external environmental agents and has two critical functions: to prevent the entry of harmful intraluminal microorganisms, antigens, and toxins, and to enable the selective translocation of dietary nutrients and electrolytes into circulation (Salminen and Isolauri, 2006; Salzman, 2011; Elson and Cong, 2012). One of the basic properties of gut-associated lymphoid tissue (GALT) is oral tolerance (unresponsiveness) to harmless components of microbiota and diet (Kau et al., 2011). Inappropriate immunological reactions against food compounds, such as lactose or gluten, can lead to the breakdown of oral tolerance and the development of intestinal immune disorders (Marsh, 1992; Stepniak and Koning, 2006). For example, Celiac disease (CD) is a chronic immune-mediated enteropathy of the small intestine that is triggered by dietary wheat gluten, or related rye and barley proteins in genetically susceptible individuals (Williamson and Marsh, 2002). The clinical and pathological spectrum of
CD is heterogeneous and there is no current rodent model that reproduces all aspects of human CD (Schuppan et al., 2009; Kupfer and Jabri, 2012). Patients display intestinal barrier dysfunction and altered tight junction protein expression allowing abnormal penetration of gluten-related peptides and enteric microbes, which could stimulate any subsequent immune response (Silva et al., 2012; Ströhle et al., 2013). Clinical presentation of CD can vary from a classical malabsorption syndrome to more subtle atypical gastrointestinal manifestations (similar to irritable bowel syndrome) or extra intestinal presentations (infertility, osteoporosis, and iron-deficiency anemia; James, 2005; Bianchi and Bardella, 2008; Bianchi, 2010; Assimakopoulos et al., 2011; Leffler, 2011). Likewise, the composition of the diet, also has a tremendous impact in digestibility and gut health of chickens (Dunsford et al., 1989; Hrncir et al., 2008; Maslowski and Mackay, 2011). A specific example is rye-based diets versus traditional corn-based diets, where different cereals are used as the principal source of energy. The inclusion of rye in poultry diets has been 
fraught with problems, principally related to the production of sticky droppings, malabsorption syndrome, elevated feed conversion, and intestinal bacterial overgrowth (Campbell et al., 1983; Bedford and Schulze, 1998; Shirzadi et al., 2010). The purpose of the present study was to evaluate the utilization of rye as energy source on bacterial translocation (BT), intestinal viscosity, microbiota composition and bone mineralization when compared with a traditional cereal (corn) in broiler chickens.

\section{MATERIALS AND METHODS}

\section{ANIMAL SOURCE AND EXPERIMENTAL DESIGN}

In order to show that the same or similar results can be achieved independently, two experiments were conducted in the present study. In each experiment, forty broiler chickens were obtained from Cobb-Vantress (Siloam Springs, AR, USA); the number of animals used was based on published studies in which similar outcomes were measured (Campbell et al., 1983; Zhang and Coon, 1997; Higgins et al., 2010a,b, 2011). Chickens were randomly assigned to two groups ( $n=20$ chickens), and placed into isolator chambers in a controlled age-appropriate environment with unrestricted access to feed and water for 10 days. All animal handling procedures were in compliance with Institutional Animal Care and Use Committee at the University of Arkansas. At 10 days of age, in both experiments, 12 chickens in both treatment groups were randomly selected, and given an oral gavage dose of fluorescein isothiocyanate dextran (FITC-d; 2.2 mg/mL/bird; MW 3,000-5,000 Da; Sigma Aldrich Co., St. Louis, MO, USA). After $2.5 \mathrm{~h}$ they were humanly killed. Blood samples were collected from the femoral vein for measuring leakage of FITC-d. Liver was collected to evaluate BT. Duodenal, ileal, and cecum gut sections were collected to enumerate bacteria. For intestinal viscosity, five chickens from each group were humanly killed and intestinal digesta were individually collected. Additionally, tibias were collected for bone parameters as describe below.

\section{DIETS}

The rye used in this research contained: $2710 \mathrm{Kcal}$ of metabolizable energy, $12.6 \%$ of crude protein, $2.8 \%$ of crude fiber, $0.40 \%$ of Lysine, $0.16 \%$ of methionine, $0.08 \%$ of calcium, and $0.3 \%$ of phosphorus. In the case of corn it contained: $3350 \mathrm{Kcal}$ of metabolizable energy, $8.27 \%$ of crude protein, $0.24 \%$ of Lysine, $0.15 \%$ of methionine, $0.01 \%$ of calcium, and $0.28 \%$ of phosphorus (Table 1). The differences in the nutritional composition of the two cereals used as principal sources of energy explain the variation between the experimental diets, which were formulated to approximate the nutritional requirements proposed by the National Research Council (1994). Due to a lower energetic contribution of rye, it was required to increase the percentage of inclusion of fat in this diet. On the contrary, in the case of crude protein in the corn diet, it was required to use a higher amount of soybeans in the feed formula to fulfill the nutritional requirements, because of the minor contribution of corn as a protein source. The small difference showed in the percentage of inclusion of lysine (L-Lysine HCL) and methionine (DL-Methionine) as purified amino acids in the diets is due to differences in amount and nutritional composition of soybean, corn, and rye in used in
Table 1 | Ingredients (\%) of the corn and rye diets used in Experiments 1 and 2.

\begin{tabular}{|c|c|c|}
\hline Item & Corn diet & Rye diet \\
\hline \multicolumn{3}{|l|}{ Ingredients } \\
\hline Corn & 55.53 & 0.0 \\
\hline Rye & 0.00 & 58.27 \\
\hline Soybean meal & 35.69 & 31.16 \\
\hline Vegetable oil & 4.22 & 6.29 \\
\hline Dicalcium phosphate & 1.82 & 1.79 \\
\hline Calcium carbonate & 1.12 & 1.05 \\
\hline Salt & 0.38 & 0.38 \\
\hline DL-METHIONINE & 0.37 & 0.35 \\
\hline Vitamin premix ${ }^{1}$ & 0.20 & 0.20 \\
\hline L-LYSINE HCL & 0.28 & 0.22 \\
\hline Choline chloride $60 \%$ & 0.20 & 0.10 \\
\hline Mineral premix ${ }^{2}$ & 0.10 & 0.10 \\
\hline Selenium $0.6 \%$ & 0.02 & 0.02 \\
\hline Propionic acid & 0.02 & 0.02 \\
\hline Antioxidant ${ }^{3}$ & 0.05 & 0.05 \\
\hline Total & 100.00 & 100.0 \\
\hline
\end{tabular}

${ }^{1}$ Vitamin premix supplied the following per $\mathrm{kg}$ : vitamin A, 20,000,000 IU; vitamin D3, 6,000,000 IU; vitamin E, 75,000 IU; vitamin K3, 9 g; thiamine, $3 \mathrm{~g}$; riboflavin, $8 \mathrm{~g}$; pantothenic acid, $18 \mathrm{~g}$; niacin, $60 \mathrm{~g}$; pyridoxine, $5 \mathrm{~g}$; folic acid, $2 \mathrm{~g}$; biotin, $0.2 \mathrm{~g}$; cyanocobalamin, $16 \mathrm{mg}$; and ascorbic acid, $200 \mathrm{~g}$ (Nutra Blend LLC, Neosho, MO 64850, USA).

${ }^{2}$ Mineral premix supplied the following per $\mathrm{kg}$ : manganese, $120 \mathrm{~g}$; zinc, $100 \mathrm{~g}$; iron, $120 \mathrm{~g}$; copper, 10-15 g; iodine, $0.7 \mathrm{~g}$; selenium, $0.4 \mathrm{~g}$; and cobalt, $0.2 \mathrm{~g}$ (Nutra Blend LLC, Neosho, MO 64850, USA).

${ }^{3}$ Ethoxyquin.

each diet (Table 1). However, both diets satisfy the amino acid requirements for maintenance and growth according to age, sex, and genetic line of the animals used in the present experiment. Broilers in the starter period ( $0-10$ days of age) required between 21 and $22 \%$ of crude protein, $3035 \mathrm{Kcal}$ of metabolizable energy, $1.32 \%$ of Lysine, $0.50 \%$ of Methionine, $0.90 \%$ of Calcium, and $0.45 \%$ of available phosphorus, all this specifications were taken into account to formulate and prepare the diets used in the present study.

\section{VISCOSITY}

Total intestinal digesta contents were collected from Meckel's diverticulum to the ileocecocolonic junction. For viscosity analysis, approximately $1.5 \mathrm{~g}$ (wet weight) of the fresh digesta was immediately placed in a microcentrifuge tube and centrifuged at $12,000 \times g$ at $4^{\circ} \mathrm{C}$ for $5 \mathrm{~min}$. The supernatant fluid was collected and stored on ice until viscosity measurement was determined using a LVDV-I Brookfield digital cone-plate viscometer fitted with a CP-40 spindle (Brookfield Engineering, Middleboro, MA, USA). The analyzed samples and the viscometer cup were maintained at $40^{\circ} \mathrm{C}$ during viscosity measurement. Viscosity was measured in centipoise $\left(\mathrm{cP}=1 / 100\right.$ dyne $\left.\mathrm{s} / \mathrm{cm}^{2}\right)$ and the results were reported as $\log _{10} \mathrm{cP}$. 


\section{BACTERIAL TRANSLOCATION}

Briefly, the right half of the liver was removed from each chicken, collected in sterile bags, homogenized, weighed and 1:4 wt/vol dilutions were made with sterile $0.9 \%$ saline. Ten-fold dilutions of each sample, from each group were made in a sterile 96 well Bacti flat bottom plate and the diluted samples were plated on MacConkey Agar (VWR Cat. No. 89429-342 Suwanee, GA 30024, USA). Biochemical evaluation tests as well as identification of isolated colonies were carried out using a bioMerieux API $50 \mathrm{CH}$ test kit (catalog no. 50430, bioMerieux, Marcy l'Etoile, France).

\section{SERUM DETERMINATION OF FITC-d}

Blood was kept at room temperature for $3 \mathrm{~h}$ and centrifuged $(1,000 \times g$ for $15 \mathrm{~min})$ to separate the serum from the red blood cells. FITC-d levels of undiluted serum were measured at excitation wavelength of $485 \mathrm{~nm}$ and emission wavelength of $528 \mathrm{~nm}$ (Synergy HT, Multi-mode microplate reader, BioTek Instruments, Inc., Vermont, USA). Fluoroscence measured was then compared to a standard curve with known FITC-d concentrations. Gut leakage for each bird was reported as $\mu \mathrm{g}$ of FITC-d/mL of serum.

\section{ENUMERATION OF BACTERIA}

Whole duodenum, ileum, and both ceca were aseptically removed, separated into sterile bags, and homogenized. Samples were weighed and 1:4 wt/vol dilutions were made with sterile $0.9 \%$ saline. Ten-fold dilutions of each sample, from each group were made in a sterile 96 well Bacti flat bottom plate and the diluted samples were plated on three different culture media; to evaluate total number of lactic acid bacteria (LAB) in Man Rogosa Sharpe (Difco Lactobacilli MRS Agar VWR Cat. No. 90004-084 Suwanee, GA 30024, USA); total Enterobacteriaceae in MacConkey; and total anaerobes in tryptic soy agar with sodium thioglycolate plates (Tryptic Soy Agar, catalog no. 211822, Becton Dickinson, Sparks, MD, USA).

\section{BONE PARAMETERS}

Bone parameters were measured according to the methods as described by Zhang and Coon (1997). Tibias from each chicken were cleaned of attached tissues. Bones from the left leg were subjected to conventional bone assays and tibia from the right leg was used to determine breaking strength. The bones from left tibia were dried at $100^{\circ} \mathrm{C}$ for $24 \mathrm{~h}$ and weighed again. The samples were then incinerated in a muffle furnace (Isotemp muffle furnace, Fisher Scientific, Pittsburgh, PA, USA) at $600^{\circ} \mathrm{C}$ for $24 \mathrm{~h}$ in crucibles. Finally, the content of calcium and phosphorus in the tibia was determined using standard methods (AOAC International, 2000) and were reported as percentage of dry matter. The right tibial diaphyses from individual birds were cleaned of adherent tissues, the periosteum was removed, and the biomechanical strength of each bone was measured using an Instron 4502 (Norwood, MA, USA) material testing machine with a $100 \mathrm{~kg}$ Load Cell. The bones were held in identical positions and the mid-diaphyseal diameter of the bone at the site of impact was measured using a dial caliper. The maximum load at failure was determined using a three-point flexural bend fixture with a total distance of $30 \mathrm{~mm}$ between the two lower supporting ends. The load, defined as force in kilograms per square millimeter of cross-sectional area $\left(\mathrm{kg} / \mathrm{mm}^{2}\right)$, represents bone strength. The rate of loading was kept constant at $20 \mathrm{~mm} / \mathrm{min}$ collecting 10 data points per second. The data were automatically calculated using Instron's Series IX Software (Norwood, MA, USA).

\section{STATISTICAL ANALYSIS}

All data were subjected to one-way analysis of variance as a completely randomized design using the General Linear Models procedure of SAS (SAS Institute, 2002). Data are expressed as mean \pm standard error. Significant differences among the means were determined by using Duncan's multiple-range test at $p<0.05$.

\section{RESULTS}

The evaluation of body weight, intestinal viscosity, serum FITC-d, and liver BT in broiler chickens fed with a corn diet or a rye diet of Experiment 1 and 2 are summarized in Table 2. A significant $(p<0.05)$ reduction in body weight was observed in chickens fed with rye as compared with corn in both experiments. However, chickens fed with rye showed a increase in intestinal viscosity which was associated with elevated $(p<0.05)$ serum FITC-d, and an increase in BT to the liver (Table 2). Identification of the Gramnegative lactose positive bacteria in the liver was confirmed to be Escherichia coli.

Table 2 | Evaluation of body weight, intestinal viscosity, serum FITC-d, and liver bacterial translocation in chickens fed with corn or rye in Experiments 1 and 2.

\begin{tabular}{|c|c|c|c|c|}
\hline \multicolumn{5}{|c|}{ Experiment 1} \\
\hline Rye & $110.69 \pm 5.21^{b}$ & $2.84 \pm 0.57^{a}$ & $0.42 \pm 0.05^{a}$ & $1.35 \pm 0.45^{a}$ \\
\hline \multicolumn{5}{|c|}{ Experiment 2} \\
\hline
\end{tabular}

Data is express as Mean $\pm S E$. Intestinal viscosity is expressed in $\log _{10}$ (in centipoise, $c P=1 / 100$ dyne s/cm ${ }^{2}$ ) from five chickens. Serum FITC-d and liver BT (expressed in cfu $\log _{10} / g$ of tissue) from 12 chickens. ${ }^{a, b}$ within columns indicate significant difference at $p<0.05$. 
Total bacterial counts in duodenum, ileum, and ceca of chickens fed with a corn or rye diet in Experiments 1 and 2 are summarized in Table 3. In both trials, chickens that were fed with rye had a significant increase in the number of total LAB that were observed in the duodenum, in the ileum, and in the ceca when compared with chickens fed with corn. In these chickens, a significant increase in the total number of coliforms was also observed in duodenum and ileum but not in cecum, whereas, an increase in total number of anaerobes was observed only in the duodenum.

The results of the evaluation of bone breaking strength and bone parameters in chickens fed with corn or rye in Experiments 1 and 2 are summarized in Table 4 . Significant increases in tibia diameter, tibia breaking strength, tibia ash, and calcium and phosphorus percentages were observed in chickens that fed corn when compared with chickens that fed the rye diet (Table 4).

\section{DISCUSSION}

In recent years, nutrition research has moved from classical epidemiology and physiology to molecular biology and genetics. Modern nutritional research is aimed at health promotion, at disease prevention, and on performance improvement (Kussmann et al., 2008). Hence, nutritional sciences are discovering the application of the so called "omics" sciences (Ghosh and Poisson, 2009;
Dimitrov, 2011). Nutritional genomics is a recent off-shoot of this genetic revolution. As a consequence of these ambitious objectives, the disciplines "nutrigenetics" and "nutrigenomics" have evolved (Afman and Müller, 2006). in particular, nutrigenomics, is the junction between health, diet, and genomics, it can be seen as the combination of molecular nutrition and genomics, addressing the inverse relationship, which is how diet influences gene transcription, protein expression, and metabolism. (Davis and Milner, 2004; Trujillo et al., 2006; Wishart, 2008; García-Cañas et al., 2010). With emerging “omics” technologies, scientists are now better able to investigate how dietary food components can affect physiological functions and the underlying cellular and molecular mechanisms implicated in the digestive process (Ghosh and Poisson, 2009; Dimitrov, 2011). Nutritionrelated genomics technology has revolutionized the field of nutrition providing unprecedented opportunities for increasing our understanding of how nutrients modulate gene and protein expression to influence cellular metabolism (Davis and Milner, 2004; Trujillo et al., 2006; Subbiah, 2007; Wishart, 2008; García-Cañas et al., 2010).

When integrated with other "omics" technologies in a biological system approach, novel nutrition-based intervention strategies are expected to provide an effective alternative for disease control.

Table 3 | Evaluation of total bacterial counts in duodenum, ileum, or cecum in chickens fed with corn or rye in Experiments 1 and 2.

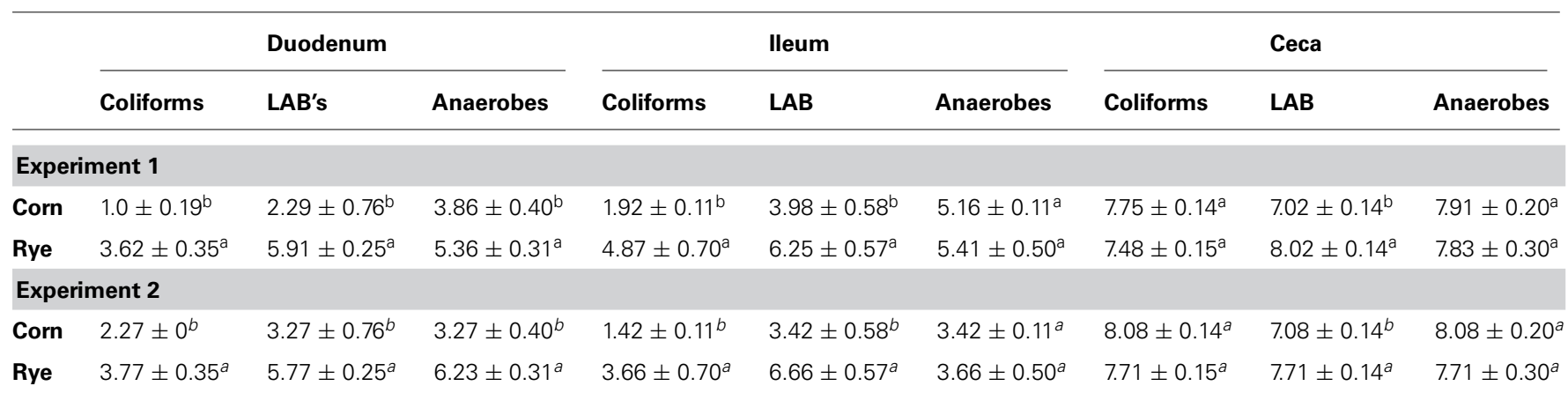

Data is express in $\log _{10} \mathrm{cfu} / \mathrm{g}$ of tissue. Mean \pm SE from 12 chickens. LAB. ${ }^{\mathrm{a}, \mathrm{b}}$ within columns indicate significant difference at $p<0.05$.

Table 4 | Evaluation of bone breaking strength and bone composition parameters in chickens fed with corn or rye based diets in Experiments 1 and 2.

$\begin{array}{lllll}\text { Tibia strength } & \text { Tibia diameter } & \text { Total ash } & \text { Calcium (\% } & \text { Phosphorus } \\ \text { Load at yield }\left(\mathrm{kg} / \mathrm{mm}^{2}\right) & (\mathrm{mm}) & \text { from tibia }(\%) & \text { of ash) } & (\% \text { of ash) }\end{array}$

\begin{tabular}{|c|c|c|c|c|c|}
\hline \multicolumn{6}{|c|}{ Experiment 1} \\
\hline Corn & $5.04 \pm 0.011^{a}$ & $3.34 \pm 0.17^{a}$ & $55.01 \pm 0.41^{a}$ & $29.48 \pm 0.27^{a}$ & $18.15 \pm 0.12^{a}$ \\
\hline Rye & $1.58 \pm 0.009^{b}$ & $1.61 \pm 0.28^{b}$ & $34.87 \pm 0.35^{b}$ & $18.48 \pm 0.27^{b}$ & $13.15 \pm 0.12^{b}$ \\
\hline \multicolumn{6}{|c|}{ Experiment 2} \\
\hline Corn & $6.14 \pm 0.01^{a}$ & $4.55 \pm 0.32^{a}$ & $65.61 \pm 0.81^{a}$ & $37.65 \pm 0.07^{a}$ & $21.35 \pm 0.52^{a}$ \\
\hline Rye & $2.58 \pm 0.03^{b}$ & $1.82 \pm 0.78^{b}$ & $30.87 \pm 0.75^{b}$ & $21.32 \pm 0.46^{b}$ & $15.67 \pm 0.29^{b}$ \\
\hline
\end{tabular}

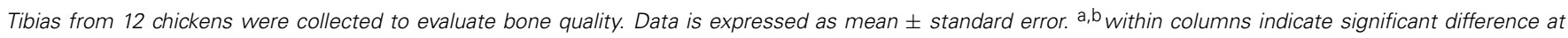
$p<0.05$ 
Several studies in poultry have been conducted to investigate the effects of probiotics and phytonutrients on the translational regulation of genes associated with immunology, pathogen control, physiology, and metabolism using high-throughput microarray analysis and in vivo disease challenge models (Tellez et al., 1993; Higgins et al., 2007, 2008, 2010a,b, 2011; Timbermont et al., 2010; Lillehoj et al., 2011; Jerzsele et al., 2012; Kiarie etal., 2013; Layton etal., 2013). Chicken has been an important experimental system for developmental biology, immunology, and microbiology for more than 2 millennia (Stern, 2004) having led to many fundamental discoveries (Burt, 2007). With the evolution of sequencing of the genome and the development of high-throughput tools for the exploration of functional elements of the genome, chicken has attained a model organism status (Stern, 2005; Dodgson, 2007). The increase in genomic resources, easy access to the embryo, and the application of RNA interference showed that it will be easy and quick to use chicken embryos to screen the function of many genes during embryonic development (Stern, 2004). So, it seems likely that chicken will increasingly be the system of choice for many vertebrate biologists, especially in the field of human sciences, who are interested in gene function (Aggarwal and Lee, 2003; Hillier et al., 2004; Cogburn et al., 2007).

Thousands of years of evolution shaped the digestive system of the jungle fowl and wild pig to deal with the dietary ingredients they encounter in an efficient manner. More recently, throw intensive genetic manipulation, nutrition, and health programs we have altered the biology and growth potential of chickens and pigs among other productive animals (Muramatsu et al., 1990; Fuller et al., 1995). In the wild, the diets of these animals would be made up of many different ingredients, few of which would ever reach $>30 \%$ of total intake on a lifetime basis. The range in types and relative quantities of ingredients that can be presented to the modem commercial monogastric animals, while complex, tend to result in a diet in which two or three ingredients may constitute $>75 \%$ of intake (National Research Council, 1994). Such change is driven by least cost formulation processes, and endeavors to provide maximum nutrient density for minimum cost (Bedford and Schulze, 1998). Corn is usually the main source of energy in poultry diets, but at times it is difficult to formulate least cost diets using corn and unconventional grains have to be used. When chickens are fed alternative grains such wheat or rye that are high in non-starch polysaccharides (NSPs), poor performance and unmanageable litter conditions caused by sticky droppings are reported (Campbell et al., 1983; Fengler and Marquardt, 1988; Choct etal., 1995). Wheat or rye contains high concentrations of NSPs, leading to reduced digestibility. In addition, high NSPs diets have also been associated with Necrotic Enteritis (NE), a multi-factorial disease caused by Clostridium perfringens $(\mathrm{CP})$ that is probably the most important bacterial disease in terms of economic implications in broiler chickens (Hofacre, 2001; Annett et al., 2002; Timbermont et al., 2011). NSPs, are comprised mainly of highly branched arabinoxylans, increassig digesta viscosity responsible for poor digestibility through interference with the movement of particles and solutes across the intestinal lumen, preventing the access of digestive enzymes to the endosperm contents and reducing intestinal absorption of sodium and calcium (Fengler and Marquardt, 1988). In addition, increased digesta viscosity reduce conjugated bile acid, affecting fat emulsification and fat digestibility (Langhout et al., 1997). In the present study, the significant reduction in bone strength and mineralization (Table 4) confirmed previous studies that have shown that high NSPs diets in poultry or gluten intolerance in humans, are also associated with malabsorption of minerals and fat-soluble vitamins (MacAuliffe and McGinnis, 1971; Campbell et al., 1983; Rennie et al., 1993; Bianchi and Bardella, 2008; Capriles et al., 2009; Kotake et al., 2009; Wideman and Prisby, 2011). In our two experiments, the viscosity of the gut in chickens fed with rye was so extreme, the supernatant being more semi-solid than fluid, that it alone could be directly responsible for the poor performance (Table 2). Condensed feed passage rate increases the time available for digesta associated bacteria to multiply prior to evacuation in the feces, and provides more substrate availability in the distal parts of the small intestine for microbial fermentation (Choct et al., 1995; Murphy et al., 2009; Kiarie et al., 2013). In the present study, the increase intestinal viscosity observed in chickens fed with rye was also associated with elevated BT, increased serum FITC-d and bacterial overgrowth when compared with chickens fed with corn (Tables 2 and $\mathbf{3}$ ). Variations in the composition of the microbiome within different segments of the alimentary tract are influenced by the environment, by the diet, and by the host (Ouwehand et al., 2002; Xu and Gordon, 2003; Hooper, 2004; Mazmanian et al., 2008). Alterations in gut permeability are connected with BT in the portal and/or systemic circulation in several types of leaky gut syndromes leading to systemic bacterial infections (Ilan, 2012; Seki and Schnabl, 2012). Similarly, FITC-d is a large molecule (3-5 kDa) which does not usually leak through the intact gastrointestinal tract barrier. However, when conditions disrupt the tight junctions between epithelial cells, the FITC-d molecule can enter circulation as demonstrated by an increase in trans-mucosal permeability associated with chemically induced disruption of tight junctions by elevated serum levels of FITC-d after oral administration (Yan et al., 2009). Since poultry has little or no intrinsic enzymes capable of hydrolyzing these NSPs, exogenous xylanases as additives are used in an attempt to reduce this antinutritive factors (Bedford et al., 1991; Bedford and Classen, 1993; Bedford and Schulze, 1998). Previously, we have evaluated the inclusion of selected direct-fed microbial (DFM) candidates that produce exogenous enzymes (protease, phytase, lipase, xylanase, and cellulose) in high NSPs diets (rye, wheat, barley, and oat). In those studies, a significant reduction in both viscosity and C. perfringens proliferation was observed between high NSPs control non-treated diets or the same diets supplemented with DFM in vitro (Latorre et al., 2014; Tellez et al., 2014). The results of the present study have confirmed in some extent our earlier in vitro findings. Together, they represent a step toward the application of nutrigenomics in the context of a chicken model. The incorporation of one or more "omics" techniques (in particular, assessment of the microbiome) will provide a better understanding of how dietary food components can affect physiological functions and the fundamental cellular and molecular mechanisms implicated in the digestive process of high NSPs diets in chickens. 
In conclusion, the use of rye as an energy source increased intestinal viscosity, increased BT, and leakage of FITC-d, altered the microbiota composition as well as bone mineralization in chickens. Studies to evaluate dietary inclusion of selected DFM candidates that produce exogenous enzymes in rye fed chickens are currently being evaluated.

\section{ACKNOWLEDGMENTS}

The authors gratefully acknowledge the excellent technical assistance of Scott Zornes (Poultry Production and Product Safety Research Unit, United States Department of Agriculture, Agricultural Research Service, Poultry Science Center, University of Arkansas, Fayetteville).

\section{REFERENCES}

Afman, L., and Müller, M. (2006). Nutrigenomics: from molecular nutrition to prevention of disease. J. Am. Diet. Assoc. 106, 569-576. doi: 10.1016/j.jada.2006.01.001

Aggarwal, K., and Lee, K. H. (2003). Functional genomics and proteomics as a foundation for systems biology. Brief. Funct. Genomic. Proteomic. 2, 175-184. doi: 10.1093/bfgp/2.3.175

Annett, C. B., Viste, J. R., Chirino-Trejo, M., Classen, H. L., Middleton, D. M., and Simko, E. (2002). Necrotic enteritis: effect of barley, wheat and corn diets on proliferation of Clostridium perfringens type A. Avian Pathol. 31, 598-601. doi: 10.1080/0307945021000024544

AOAC International. (2000). "Animal feeds," in Official Methods of Analysis of AOAC International, 17th Edn., Vol. 1. ed. W. Horwaitz. (Gaithersburg, MD: AOAC International), 1-54.

Assimakopoulos, S. F., Papageorgiou, I., and Charonis, A. (2011). Enterocytes' tight junctions: from molecules to diseases. World J. Gastrointest. Pathophysiol. 2, 123-137. doi: 10.4291/wjgp.v2.i6.123

Bedford, M. R., and Classen, H. L. (1993). An in vitro assay for prediction of broiler intestinal viscosity and growth when fed rye-based diets in the presence of exogenous enzymes. Poult. Sci. 72, 137-143. doi: 10.3382/ps.0720137

Bedford, M. R., Classen, H. L., and Campbell, G. L. (1991). The effect of pelleting, salt, and pentosanase on the viscosity of intestinal contents and the performance of broilers fed rye. Poult. Sci. 70, 1571-1577. doi: 10.3382/ps.0701571

Bedford, M. R., and Schulze, H. (1998). Exogenous enzymes for pigs and poultry. Nutr. Res. Rev. 11, 91-114. doi: 10.1079/NRR19980007

Bianchi, M. L. (2010). Inflammatory bowel diseases, celiac disease, and bone. Arch Biochem. Biophys. 503, 54-65. doi: 10.1016/j.abb.2010.06.026

Bianchi, M. L., and Bardella, M. T. (2008). Bone in celiac disease. Osteoporos. Int. 19, 1705-1716. doi: 10.1007/s00198-008-0624-0

Burt, D. W. (2007). Emergence of the chicken as a model organism: implications for agriculture and biology. Poult. Sci. 86, 1460-1471. doi: 10.1093/ps/86.7.1460

Campbell, G. L., Campbell, L. D., and Classen, H. L. (1983). Utilisation of rye by chickens: effect of microbial status, diet gamma irradiation and sodium taurocholate supplementation. Br. Poult. Sci. 24, 191-203. doi: 10.1080/00071668308416730

Capriles, V. D., Martini, L. A., and Arêas, J. A. (2009). Metabolic osteopathy in celiac disease: importance of a gluten-free diet. Nutr. Rev. 67, 599-606. doi: 10.1111/j.1753-4887.2009.00232.x

Choct, M., Hughes, R. J., Trimble, R. P., Angkanaporn, K., and Annison, G. (1995). Non-starch polysaccharide-degrading enzymes increase the performance of broiler chickens fed wheat of low apparent metabolizable energy. J. Nutr. 125, 485-492.

Cogburn, L. A., Porter, T. E., Duclos, M. J., Simon, J., Burgess, S. C., Zhu, J. J., et al. (2007). Functional genomics of the chicken-a model organism. Poult. Sci. 86, 2059-2094. doi: 10.1093/ps/86.10.2059

Davis, C. D., and Milner, J. (2004). Frontiers in nutrigenomics, proteomics, metabolomics and cancer prevention. Mutat. Res. 551, 51-64. doi: 10.1016/j.mrfmmm.2004.01.012

Dimitrov, D. V. (2011). The human gutome: nutrigenomics of the host-microbiome interactions. OMICS 15, 419-430. doi: 10.1089/omi.2010.0109

Dodgson, J. B. (2007). The chicken genome: some good news and some bad news. Poult. Sci. 86, 1453-1459. doi: 10.1093/ps/86.7.1453
Dunsford, B. R., Knabe, D. A., and Haensly, W. E. (1989). Effect of dietary soybean meal on the microscopic anatomy of the small intestine in the early-weaned pig. J. Anim. Sci. 67, 1855-1863.

Elson, C. O., and Cong, Y. (2012). Host-microbiota interactions in inflammatory bowel disease. Gut Microbes 3, 332-344. doi: 10.4161/gmic.20228

Fengler, A. I., and Marquardt, R. R. (1988). Water soluble pentosans from rye. I. Isolation, partial purification, and characterization. Cereal Chem. 65, 291-297.

Fuller, M. F., Franklin, M. F., McWilliam, R., and Pennie, K. (1995). The responses of growing pigs, of different sex and genotype, to dietary energy and protein. Anim. Sci. 60, 291-298. doi: 10.1017/S1357729800008456

García-Cañas, V., Simó, C., León, C., and Cifuentes, A. (2010). Advances in Nutrigenomics research: novel and future analytical approaches to investigate the biological activity of natural compounds and food functions. J. Pharm. Biomed. Anal.51, 290-304. doi: 10.1016/j.jpba.2009.04.019

Ghosh, D., and Poisson, L. M. (2009). "Omics" data and levels of evidence for biomarker discovery. Genomics 93, 13-16. doi: 10.1016/j.ygeno.2008.07.006

Higgins, J., Higgins, S., Vicente, J., Wolfenden, A., Tellez, G., and Hargis, B. (2007). Temporal effects of lactic acid bacteria probiotic culture on Salmonella in neonatal broilers. Poult. Sci. 86, 1662-1666. doi: 10.1093/ps/86.8.1662

Higgins, J., Higgins, S., Wolfenden, A., Henderson, S., Torres-Rodriguez, A., Vicente, J., et al. (2010a). Effect of lactic acid bacteria probiotic culture treatment timing on Salmonella enteritidis in neonatal broilers. Poult. Sci. 89, 243-247. doi: 10.3382/ps.2009-00436

Higgins, S. E., Ellestad, L. E., Trakooljul, N., McCarthy, F., Saliba, J., Cogburn, L. A., et al. (2010b). Transcriptional and pathway analysis in the hypothalamus of newly hatched chicks during fasting and delayed feeding. BMC Genomics 11:162. doi: 10.1186/1471-2164-11-162

Higgins, J. P., Andreatti Filho, R. L., Higgins, S. E., Wolfenden, A. D., Téllez, G., and Hargis, B. M. (2008). Evaluation of Salmonella-lytic properties of bacteriophages isolated from commercial broiler houses. Avian Dis. 52, 139-142. doi: 10.1637/8017-050807-ResNote

Higgins, S., Wolfenden, A., Tellez, G., Hargis, B., and Porter, T. (2011). Transcriptional profiling of cecal gene expression in probiotic-and Salmonella-challenged neonatal chicks. Poult. Sci. 90, 901-913. doi: 10.3382/ps.2010-00907

Hillier, L. W., Miller, W., Birney, E., Warren, W., Hardison, R. C., Ponting, C. P., et al. (2004). Sequence and comparative analysis of the chicken genome provide unique perspectives on vertebrate evolution. Nature 432, 695-716.

Hofacre, C. L. (2001). "Necrotic enteritis, currently a billion dollar disease: is there anything new on the horizon," in Proceedings of Alltech's 17th Annual Symposium Science and Technology in the Feed Industry, eds T. P. Lyons and K. A. Jacques (Nottingham: Nottingham University Press), 79-86.

Hooper, L. V. (2004). Bacterial contributions to mammalian gut development. Trends Microbiol. 12, 129-134. doi: 10.1016/j.tim.2004.01.001

Hrncir, T., Stepankova, R., Kozakova, H., Hudcovic, T., and Tlaskalova-Hogenova, H. (2008). Gut microbiota and lipopolysaccharide content of the diet influence development of regulatory T cells: studies in germ-free mice. BMC Immunol. 9:65. doi: 10.1186/1471-2172-9-65

Ilan, Y. (2012). Leaky gut and the liver: a role for bacterial translocation in nonalcoholic steatohepatitis. World J. Gastroenterol. 18, 2609-2618. doi: 10.3748/wjg.v18.i21.2609

James, S. P. (2005). Prototypic disorders of gastrointestinal mucosal immune function: Celiac disease and Crohn's disease. J. Allergy Clin. Immunol. 115, 25-30. doi: 10.1016/j.jaci.2004.11.011

Jerzsele, A., Szeker, K., Csizinszky, R., Gere, E., Jakab, C., Mallo, J. J., et al. (2012). Efficacy of protected sodium butyrate, a protected blend of essential oils, their combination, and Bacillus amyloliquefaciens spore suspension against artificially induced necrotic enteritis in broilers. Poult. Sci. 91, 837-843. doi: 10.3382/ps.2011-01853

Kau, A. L., Ahern, P. P., Griffin, N. W., Goodman, A. L., and Gordon, J. I. (2011). Human nutrition, the gut microbiome and the immune system. Nature 474, 327-336. doi: 10.1038/nature10213

Kiarie, E., Romero, L. F., and Nyachoti, C. M. (2013). The role of added feed enzymes in promoting gut health in swine and poultry. Nutr. Res. Rev. 26, 71-88. doi: 10.1017/S0954422413000048

Kotake, S., Nanke, Y., Yago, T., Kawamoto, M., and Yamanaka, H. (2009). Human osteoclastogenic T cells and human osteoclastology. Arthritis Rheum. 60, 31583163. doi: 10.1002/art.24886 
Kussmann, M., Rezzi, S., and Daniel, H. (2008). Profiling techniques in nutrition and health research. Curr. Opin. Biotechnol. 19, 83-99. doi: 10.1016/j.copbio.2008.02.003

Kupfer, S. S., and Jabri, B. (2012). Pathophysiology of celiac disease. Gastrointest. Endosc. Clin. N. Am. 22, 639-660. doi: 10.1016/j.giec.2012.07.003

Langhout, D. J., Schutte, J. B., Geerse, C., Kies, A. E., De Jong, J., and Verstegen, M. W. (1997). Effects on chick performance and nutrient digestibility of an endoxylanase added to a wheatand rye-based diet in relation to fat source. Br. Poult Sci. 38, 557-563. doi: 10.1080/00071669708418036

Latorre, J. D., Wolfenden, R., Vicente, J. L., Menconi, A., Wolfenden, A., Bielke, L. R., et al. (2014). "Evaluation of enzyme production, biofilm synthesis, viscosity, and germination/sporulation rate of a Bacillus spp. based commercial DFM product in different poultry diets using an in vitro digestive model," in Proceedings of the International Poultry Scientific Forum, Atlanta.

Layton, S. L., Hernandez-Velasco, X., Chaitanya, S., Xavier, J., Menconi, A., Latorre, J. D., et al. (2013). The effect of a Lactobacillus-based probiotic for the control of necrotic enteritis in broilers. Food Nutr. Sci. 4, 1-7. doi: 10.4236/fns.2013.411A001

Leffler, D. (2011). Celiac disease diagnosis and management: a 46-year-old woman with anemia. JAMA 306, 1582-1592. doi: 10.1001/jama.2011.1312

Lillehoj, H. S., Kim, D. K., Bravo, D. M., and Lee, S. H. (2011). Effects of dietary plantderived phytonutrients on the genome-wide profiles and coccidiosis resistance in the broiler chickens. BMC Proc. 5(Suppl. 4):S34. doi: 10.1186/1753-65615-S4-S34

MacAuliffe, T., and McGinnis, J. (1971). Effect of antibiotic supplements to diets containing rye on chick growth. Poult. Sci. 50, 1130-1134. doi: 10.3382/ps.0501130

Marsh, M. N. (1992). Gluten, major histocompatibility complex, and the small intestine. A molecular and immunobiologic approach to the spectrum of gluten sensitivity (“celiac sprue.") Gastroenterology 102, 330-354.

Maslowski, K. M., and Mackay, C. R. (2011). Diet, gut microbiota and immune responses. Nat. Immunol. 12, 5-9. doi: 10.1038/ni0111-5

Mazmanian, S. K., Round, J. L., and Kasper, D. L. (2008). A microbial symbiosis factor prevents intestinal inflammatory disease. Nature 453, 620-625. doi: 10.1038 /nature07008

Muramatsu, T., Hiratnoto, K., and Okumura, J. (1990). Strain differences in wholebody protein turnover in the chicken embryo. Br. Poult. Sci. 31, 91-99. doi: 10.1080/00071669008417234

Murphy, T. C., McCracken, J. K., McCann, M. E., George, J., and Bedford, M. R. (2009). Broiler performance and in vivo viscosity as influenced by a range of xylanases, varying in ability to effect wheat in vitro viscosity. Br. Poult. Sci. 50, 716-724. doi: 10.1080/00071660903389950

National Research Council. (1994). Nutrient Requirements of Poultry, 9th Revision $E d n$. Washington, DC: National Academic Press.

Ouwehand, A., Isolauri, E., and Salminen, S. (2002). The role of the intestinal microflora for the development of the immune system in early childhood. Eur. J. Nutr. 41, 132-137. doi: 10.1007/s00394-002-1105-4

Rennie, J. S., Whitehead, C. C., and Thorp, B. H. (1993). The effect of dietary 1 , 25-dihydroxycholecalciferol in preventing tibial dyschondroplasia in broilers fed on diets imbalanced in calcium and phosphorus. Br. J. Nutr. 69, 809-816. doi: 10.1079/BJN19930081

Salminen, S., and Isolauri, E. (2006). Intestinal colonization, microbiota, and probiotics. J. Pediatr. 149, S115-S120. doi: 10.1016/j.mib.2010.09.018

Salzman, N. H. (2011). Microbiota-immune system interaction: an uneasy alliance. Curr. Opin. Microbiol. 14, 99-105. doi: 10.1016/j.mib.2010.09.018

SAS Institute. (2002). SAS User Guide. Version 9.1. Cary, NC: SAS Institute Inc.

Schuppan, D., Junker, Y., and Barisani, D. (2009). Celiac disease: from pathogenesis to novel therapies. Gastroenterology 137, 1912-1933. doi: 10.1053/j.gastro.2009.09.008

Seki, E., and Schnabl, B. (2012). Role of innate immunity and the microbiota in liver fibrosis: crosstalk between the liver and gut. J. Physiol. 590, 447-458. doi: 10.1113/jphysiol.2011.219691

Shirzadi, H., Moravej, H., and Shivazad, M. (2010). Influence of non starch polysaccharide-degrading enzymes on the meat yield and viscosity of jejunal digesta in broilers fed wheat/barley-based diet. Afr. J. Biotechnol. 9, 1517-1522.

Silva, M. A., Jury, J., Sanz, Y., Wiepjes, M., Huang, X., Murray, J. A., et al (2012). Increased bacterial translocation in gluten-sensitive mice is independent of small intestinal paracellular permeability defect. Dig. Dis. Sci. 57, 38-47. doi: 10.1007/s10620-011-1847-z
Stepniak, D., and Koning, F. (2006). Celiac disease-sandwiched between innate and adaptive immunity. Hum. Immunol. 67, 460-468. doi: 10.1016/j.humimm.2006.03.011

Stern, C. D. (2004). The chick embryo-past, present and future as a model system in developmental biology. Mech. Dev. 121, 1011-1013. doi: 10.1016/j.mod.2004.06.009

Stern, C. D. (2005). The chick: a great model system becomes even greater. Dev. Cell 8, 9-17. doi: 10.1016/j.devcel.2004.11.018

Ströhle, A., Wolters, M., and Hahn, A. (2013). Celiac disease-the chameleon among the food intolerances. Med. Monatsschr. Pharm. 36, 369-80.

Subbiah, M. T. (2007). Nutrigenetics and nutraceuticals: the next wave riding on personalized medicine. Transl. Res. 149, 55-61. doi: 10.1016/j.trsl.2006.09.003

Tellez, G., Jaeger, L., Dean, C., Corrier, D., DeLoach, J., Williams, J., et al. (1993). Effect of prolonged administration of dietary capsaicin on Salmonella enteritidis infection in leghorn chicks. Avian Dis. 37, 143-148. doi: 10.2307/ 1591467

Tellez, G., Latorre, J. D., Wolfenden, R., Vicente, J. L., Menconi, A., Wolfenden, A., et al. (2014). "Screening of bacteriocin-like compound synthesis (BLC) from Bacillus spp: relation of diet composition, viscosity and proliferation of Clostridium perfringens in an in vitro digestive," in Proceedings of the International Poultry Scientific Forum, Atlanta.

Timbermont, L., Haesebrouck, F., Ducatelle, R., and Van Immerseel, F. (2011). Necrotic enteritis in broilers: an updated review on the pathogenesis. Avian Pathol. 40, 341-347. doi: 10.1080/03079457.2011.590967

Timbermont, L., Lanckriet, A., Dewulf, J., Nollet, N., Schwarzer, K., Haesebrouck, F., et al. (2010). Control of Clostridium perfringens-induced necrotic enteritis in broilers by target-released butyric acid, fatty acids and essential oils. Avian Pathol. 39, 117-121. doi: 10.1080/03079451003610586

Trujillo, E., Davis, C., and Milner, J. (2006). Nutrigenomics, proteomics, metabolomics, and the practice of dietetics. J. Am. Diet. Assoc. 106, 403-413. doi: 10.1016/j.jada.2005.12.002

Wideman, R. F., and Prisby, R. D. (2011). Bone circulatory disturbances in the development of spontaneous bacterial chondronecrosis with osteomyelitis: a translational model for the pathogenesis of femoral head necrosis. Front. Endocrinol. 3:183. doi: 10.3389/fendo.2012.00183

Williamson, D., and Marsh, M. N. (2002). Celiac disease. Mol. Biotechnol. 22, 293-299. doi: 10.1385/MB:22:3:293

Wishart, D. S. (2008). Metabolomics: applications to food science and nutrition research. Trends Food Sci. Technol. 19, 482-493. doi: 10.1016/j.tifs.2008.03.003

Xu, J., and Gordon, J. I. (2003). Honor thy symbionts. Proc. Natl. Acad. Sci. U.S.A. 100, 10452-10459. doi: 10.1073/pnas.1734063100

Yan, Y., Kolachala, V., Dalmasso, G., Nguyen, H., Laroui, H., Sitaraman, S. V., et al. (2009). Temporal and spatial analysis of clinical and molecular parameters in dextran sodium sulfate induced colitis. PLoS ONE 4:e6073. doi: 10.1371/journal.pone.0006073

Zhang, B., and Coon, C. N. (1997). The relationship of various tibia bone measurements in hens. Poult. Sci. 76, 1698-1701. doi: 10.1093/ps/76.12.1698

Conflict of Interest Statement: The authors declare that the research was conducted in the absence of any commercial or financial relationships that could be construed as a potential conflict of interest.

Received: 07 July 2014; paper pending published: 15 August 2014; accepted: 10 September 2014; published online: 25 September 2014.

Citation: Tellez G, Latorre JD, Kuttappan VA, Kogut MH, Wolfenden A, HernandezVelasco X, Hargis BM, Bottje WG, Bielke LR and Faulkner OB (2014) Utilization of rye as energy source affects bacterial translocation, intestinal viscosity, microbiota composition, and bone mineralization in broiler chickens. Front. Genet. 5:339. doi: 10.3389/fgene.2014.00339

This article was submitted to Nutrigenomics, a section of the journal Frontiers in Genetics.

Copyright (c) 2014 Tellez, Latorre, Kuttappan, Kogut, Wolfenden, Hernandez-Velasco, Hargis, Bottje, Bielke and Faulkner. This is an open-access article distributed under the terms of the Creative Commons Attribution License (CC BY). The use, distribution or reproduction in other forums is permitted, provided the original author(s) or licensor are credited and that the original publication in this journal is cited, in accordance with accepted academic practice. No use, distribution or reproduction is permitted which does not comply with these terms. 